\title{
Integration of Generic Multi-dimensional Model and Operational Policies for Batch Cooling Crystallization
}

\author{
Abdul Samad, Noor Asma Fazli; Singh, Ravendra; Sin, Gürkan; Gernaey, Krist; Gani, Rafiqul
}

Published in:

21st European Symposium on Computer Aided Process Engineering

Link to article, DOI:

10.1016/B978-0-444-53711-9.50018-3

Publication date:

2011

Link back to DTU Orbit

Citation (APA):

Abdul Samad, N. A. F., Singh, R., Sin, G., Gernaey, K., \& Gani, R. (2011). Integration of Generic Multidimensional Model and Operational Policies for Batch Cooling Crystallization. In 21st European Symposium on Computer Aided Process Engineering (pp. 86-90). Elsevier. Computer Aided Chemical Engineering No. 29 https://doi.org/10.1016/B978-0-444-53711-9.50018-3

\section{General rights}

Copyright and moral rights for the publications made accessible in the public portal are retained by the authors and/or other copyright owners and it is a condition of accessing publications that users recognise and abide by the legal requirements associated with these rights.

- Users may download and print one copy of any publication from the public portal for the purpose of private study or research.

- You may not further distribute the material or use it for any profit-making activity or commercial gain

- You may freely distribute the URL identifying the publication in the public portal 


\title{
Integration of Generic Multi-dimensional Model and Operational Policies for Batch Cooling Crystallization
}

\author{
Noor Asma Fazli Abdul Samad ${ }^{1}$, Ravendra Singh, Gürkan Sin ${ }^{1}$, Krist V. Gernaey ${ }^{2}$ and Rafiqul Gani* \\ (1) Computer Aided Process-Product Engineering Center (CAPEC), Department of Chemical and Biochemical \\ Engineering, Søltofts Plads, Building 229, Technical University of Denmark, DK-2800 Lyngby, Denmark \\ (2) Center for Process Engineering and Technology (PROCESS), Department of Chemical and Biochemical \\ Engineering, Søltofts Plads, Building 229, Technical University of Denmark, DK-2800 Lyngby, Denmark
}

Crystallization processes form an important class of separation methods that are frequently used in the chemical, the pharmaceutical and the food industry. The specifications of the crystal product are usually given in terms of crystal size, shape and purity. In order to predict the desired crystal morphology by means of model-based approaches, appropriate models covering the effects of the various operational parameters on the behavior of the crystals are necessary. Therefore the generic model-based framework of one dimension crystallization processes has been developed for process control and product monitoring to meet this need [1]. However the one-dimensional models only consider one inner variable (characteristic length) in the population balance equations as a measure for crystal size, thus limiting the crystal shape only to the description of spherical or cubic crystals. To fully characterize the crystal particles higher dimensional models are necessary, that is, a multi-dimensional population balance modeling approach is needed, where two- or even three- characteristic lengths of a crystal may be considered. Once the model is available, it can subsequently be used in many applications notably to obtain the required product qualities in terms of CSD and shape. Usually the main difficulty in batch cooling crystallization is to accomplish a uniform and reproducible CSD. Usually supersaturation control has been applied to drive the process within the metastable zone to enhance the control of the CSD. Although this approach has shown to produce high quality crystals, the set point operating profiles for the supersaturation controller are usually chosen arbitrarily or by trial-and error.

The objective of this work is to integrate generic multi-dimensional models with operational policies based on analytical estimators within a computer aided framework for study of batch cooling crystallization processes. Also, the paper highlights the application of the framework to study different multi-dimensional aspects of crystallization processes for a wide range of chemical systems. In order to generate an operational policy, an analytical CSD estimator has been introduced and integrated with the generic multi-dimensional model in the framework. The estimator is based on the assumptions of constant supersaturation and an operation that is dominated by size dependent growth. The generated operational policy provides the supersaturation set point and by maintaining the operation at this point, a target CSD is achieved. Compared to earlier works, additional information regarding the total crystal mass is also targeted here. The application of the multi-dimensional model-based framework is highlighted using a two-dimensional potassium dihydrogen phosphate (KDP) batch cooling crystallization process as a case study. The use of an analytical estimator for prediction of the CSD is illustrated on a potassium dichromate case study.

Keywords: multidimensional, crystal size distribution, crystal shape

Reference:

[1] Abdul Samad, N.A.F., Singh, R., Sin, G., Gernaey, K.V., Gani, R (2010). Computer-Aided Chemical Engineering Series, Volume 28, 613-618, Elsevier B.V.

* Corresponding author (Email: rag@kt.dtu.dk, Tel. +45 45252882, Fax: +45 45932906) 